\title{
Correction to: Implementation of Early Intervention Protocol in Australia for 'High Risk' Injured Workers is Associated with Fewer Lost Work Days Over 2 Years Than Usual (Stepped) Care
}

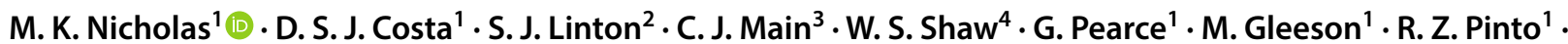 \\ F. M. Blyth ${ }^{5}$. J. H. McAuley ${ }^{6}$ R. J. E. M. Smeets ${ }^{7,8}$ - A. McGarity ${ }^{9}$
}

Published online: 14 August 2019

(c) Springer Science+Business Media, LLC, part of Springer Nature 2019

\section{Correction to: Journal of Occupational Rehabilitation https://doi.org/10.1007/s10926-019-09849-y}

The original version of this article unfortunately contained a spelling error in one of the co-author's name. The family name of the co-author was incorrectly displayed as "James McCauley" instead of "James McAuley".
The original article has been corrected.

Publisher's Note Springer Nature remains neutral with regard to jurisdictional claims in published maps and institutional affiliations.
The original article can be found online at https://doi.org/10.1007/ s10926-019-09849-y.

M. K. Nicholas

michael.nicholas@sydney.edu.au

1 Sydney Medical School - Northern, University of Sydney \& Royal North Shore Hospital, St Leonards, NSW, Australia

2 Center for Health And Medical Psychology, Department of Law, Psychology, and Social Work, Örebro University, Örebro, Sweden

3 Arthritis Care UK Primary Care Centre, Keele University, Keele, North Staffordshire, UK

4 University of Massachusetts Medical School, Worcester, MA, USA

5 School of Public Health, Concord Clinical School, University of Sydney, Sydney, NSW, Australia

6 Neuroscience Research Australia and School of Medical Sciences, University of NSW, Sydney, NSW, Australia

7 Department of Rehabilitation Medicine, Caphri, Maastricht University, Maastricht, The Netherlands

8 CIR Revalidatie, Eindhoven, The Netherlands

9 Injury Management Health \& Safety Branch, NSW Fire and Safety, Sydney, Australia 